\title{
Immunotherapy in the management of melanoma: current status
}

\author{
This article was published in the following Dove Press journal: \\ ImmunoTargets and Therapy \\ 23 February 2013 \\ Number of times this article has been viewed
}

\author{
Dylan Alston' \\ Jerry D Brewer ${ }^{2}$ \\ 'Chicago College of Osteopathic \\ Medicine, Midwestern University, \\ Downers Grove, IL, ${ }^{2}$ Mayo Clinic, \\ Rochester, MN, USA
}

Correspondence: Jerry Brewer Mayo Clinic, Department of Dermatology, 200 First Street SW, Rochester, MN 55905, USA

Tel +I 5072843579

Fax +I 5072845974

Email brewer.jerry@mayo.edu

\begin{abstract}
As the rate of melanoma continues to increase, so does the need for more effective and durable therapies. Despite considerable research, the management of advanced disease remains challenging. Numerous therapies are being investigated, many of which aim at upregulating the immune system's innate ability to attack the tumor. Cytotoxic T lymphocyte antigen 4 antibodies are immune stimulants that act as negative regulators of the immune system by modifying an antitumor T-cell response. Ipilimumab, one such cytotoxic T lymphocyte antigen 4 antibody, and vemurafenib, a BRAF competitive inhibitor, were approved as first-line therapies in 2011 due to improved survival rates versus standard chemotherapy. Allovectin-7 is a lipid plasmid that encodes for major histone compatibility complex DNA sequences. It has led to increases in cytotoxic T-cell production, which subsequently attacks the tumor. OncoVEX, an oncolytic herpes virus, and PV-10, a chemoablative agent, have yielded promising results in metastatic lesions and have demonstrated a unique "bystander" phenomenon. In this paper we review the basics of melanoma from the pathophysiology, risk factors, signs, diagnostic approaches, and current status of immunologic management of melanoma.
\end{abstract}

Keywords: melanoma, immunotherapy, ipilimumab, vemurafenib, OncoVEX, Allovectin-7

\section{Introduction}

Malignant melanoma continues to climb oncology's "top ten" most wanted list. Researchers and clinicians alike are continuing to investigate novel immunotherapies as hopeful adjuvant therapies for surgical excision and chemotherapy. Until recently, decades of research and clinical trials have struggled to demonstrate significant improved survival rates in patients with metastatic disease. ${ }^{1}$ The median survival time of 8-9 months and a 3-year survival rate of $10 \%-15 \%$ when treated with systemic chemotherapies are now being surpassed by new immunotherapies. ${ }^{2}$ As a result, traditional therapeutic approaches are being augmented with more molecular-based approaches in an attempt to yield significant improvement in survival rates.

Promising advances in systemic therapy for metastatic melanoma are evolving, particularly in the field of immunomodulation. In 2011, ipilimumab and vemurafenib were both approved as first- and second-line treatment for metastatic disease in the US and Europe. ${ }^{3-5}$ Additionally in 2011, significant survival benefit was appreciated in a combination trial of ipilimumab and dacarbazine compared with dacarbazine alone. ${ }^{6}$ Finally, numerous other modalities, including intralesional (IL) therapies, are currently being investigated. ${ }^{7}$ submit your manuscript | www.dovepress.com

Dovepress

http://dx.doi.org// $0.2147 / \mid$ TT.S30824
ImmunoTargets and Therapy 2013:2 I-10

(C) 2013 Alston and Brewer, publisher and licensee Dove Medical Press Ltd. This is an Open Access article which permits unrestricted noncommercial use, provided the original work is properly cited. 


\section{Overview of the causes,}

\section{pathophysiology, signs, symptoms, and diagnosis of melanoma}

Recognition and awareness of melanoma risk factors is an increasingly important public health concern. Identification of an individual's risk for developing melanoma can guide the decision-making process. Additionally, the threshold for obtaining a biopsy, follow-up times, as well as sun protective behavior education is determined in light of a patient's risk factor profile. Three categories encompass the most well-known risk factors for the development of melanoma: environmental exposures, genetics, and phenotypic expression. The interaction between these three categories may account for the disparity of melanoma incidence when considering age, geographic locale, and ethnic populations.

A direct cause-and-effect relationship between melanoma and ultraviolet (UV) radiation cannot be validated experimentally. Unequivocal evidence from prospective studies dispels any doubt that repeated exposure to UV radiation contributes to the pathogenesis of melanoma. ${ }^{8} \mathrm{UV}$ radiation comes in many forms and wavelengths. Exposure to natural sunlight in the form of UV-A and UV-B radiation is most commonly encountered. As a result, a latitudeassociated risk factor develops, as closer proximity to the equator bestows a larger risk. Although the precise pattern or wavelength of UV exposure that contributes to melanoma has not been elucidated, it is theorized that intermittent, highpotency exposure to nonacclimated fair skin poses a greater risk for melanoma than cumulative chronic sun exposure. ${ }^{9}$ This notion arises as a result of the counterintuitive recognition that indoor workers suffer a higher incidence of melanoma than do outdoor workers. ${ }^{10}$ Furthermore, research has uncovered an interesting relationship between socioeconomic status and melanoma incidence. Studies suggest that countries with high levels of education, high income, low poverty, and low unemployment have the highest incidence of melanoma. ${ }^{11}$

More damaging than natural sun exposure is artificial environmental exposure of UV radiation induced by tanning beds. Consequently, tanning beds have contributed drastically to the increased incidence of melanoma worldwide, especially in the sun-deprived environments of northern climates. ${ }^{12}$ Since becoming a culturally acceptable modality, some studies suggest that nearly $40 \%-50 \%$ of teenagers have utilized indoor tanning devices, whereas estimates believe that $71 \%$ of tanning salon consumers are females between the ages of 16 and 29 years. ${ }^{13}$ The primary source of radiation from tanning lamps is UV-A at intensities roughly ten times higher than what natural sunrays emit midday on a Mediterranean beach. ${ }^{14}$ The International Agency for Research on Cancer published a comprehensive review encompassing cross-sectional, case control, and cohort studies on melanoma incidence and tanning bed use. Analysis indicated that ever-use of tanning devices demonstrated a strongly positive association with melanoma, although no evidence of a dose-response relationship could be elucidated..$^{15}$ Additionally, and most strikingly, research has demonstrated that those utilizing indoor UV tanners are $74 \%$ more likely to acquire melanoma over their lifetime compared with those who have never been exposed to artificial UV radiation. ${ }^{16}$

In addition to artificial UV exposure, one of the most substantial risk factors for melanoma is a positive family history of the disease. Individuals can be predisposed to melanoma through either polymorphisms or germline mutations. Two major susceptibility genes known as $C D K N 2 A$ and $C D K 4$ are associated with high-penetrance melanomas. ${ }^{17}$ $C D K N 2 A$ encodes two discrete protein products known as $\mathrm{p} 16$ and $\mathrm{p} 14^{\mathrm{ARF}}$, which, like the protein transcribed from $C D K 4$, serve as tumor suppressor proteins in the $\mathrm{G} 1$ to $\mathrm{S}$ phases of the cell cycle. ${ }^{17}$ Although population-based studies have demonstrated the true prevalence of these mutations to be exceedingly low, they nevertheless provide insight into the tumor progression pathway. ${ }^{18}$

The primary phenotypic features associated with melanoma are genetically driven and include skin color, skin type, and number of melanocytic nevi. Skin color is determined not by the absolute number of melanocytes but rather by the size and distribution of pigmented granules within them. Skin color may, in part, explain the large variation in melanoma incidence amongst ethnic populations, as melanin serves to protect nuclear DNA against ionizing radiation. ${ }^{19}$ An abundance of common melanocytic nevi and the presence of atypical or dysplastic nevi serve as a significant risk factor for melanoma. ${ }^{10}$ Although the number of nevi one develops is mainly genetically determined, environmental factors may also influence the number of nevi and thus melanoma susceptibility. ${ }^{20}$

Melanoma has traditionally been divided into four major variations differing in their anatomic location and clinical and histologic appearance. Numerous molecular studies support the idea of unique and separate tumor progression pathways that relate to the anatomic site and degree of sun exposure. ${ }^{21}$ Furthermore, the disparity between the number of chromosomal mutations and the frequency of them implies 
that different histological subsets of melanoma may arise from distinct pathways. Currently, the molecular pathogenesis of melanoma is focusing on two mutually exclusive mutations known as BRAF and NRAS. These mutations function in the same pathway but through different mechanisms. $B R A F$ is a proto-oncogene localized to chromosome $7 \mathrm{q} 34$ and is an associate of the serine/threonine protein kinase $R A F$ family. Conversely, $N R A S$ belongs to the RAS family of small GTPases. Both BRAF and NRAS function in a cohort of regulatory proteins in the RAS-RAF-MEK-ERK molecular pathway and serve to regulate cell cycle progression, albeit at different sites (Figure 1). ${ }^{22}$ Estimates project that activating mutations in BRAF and NRAS constitute upwards of $66 \%$ and $20 \%$ of melanomas, respectively. ${ }^{23}$ Additionally, the frequency of $B R A F$ and $N R A S$ mutations appeared in $81 \%$ of melanomas characterized by intermittent sun exposure. ${ }^{23}$ Melanomas arising from mucosal and acral sites possessed higher numbers of wildtype $B R A F$ and NRAS mutations, as well as a higher prevalence of $C D K 4$ and $C C N D 1$ genes. ${ }^{24}$ Furthermore, studies have demonstrated that NRAS mutations may be associated with a thicker tumor depth and a higher mitotic rate than those with $B R A F$ (V600E) mutations. ${ }^{25}$ Conversely, BRAF (V600E) mutations were associated with more frequent and more pronounced infiltration of neighboring lymph nodes when metastasizing $(P=0.013) .{ }^{26}$ Although each mutation displays unique characteristics, neither mutation has been shown to influence overall survival (OS). ${ }^{26}$

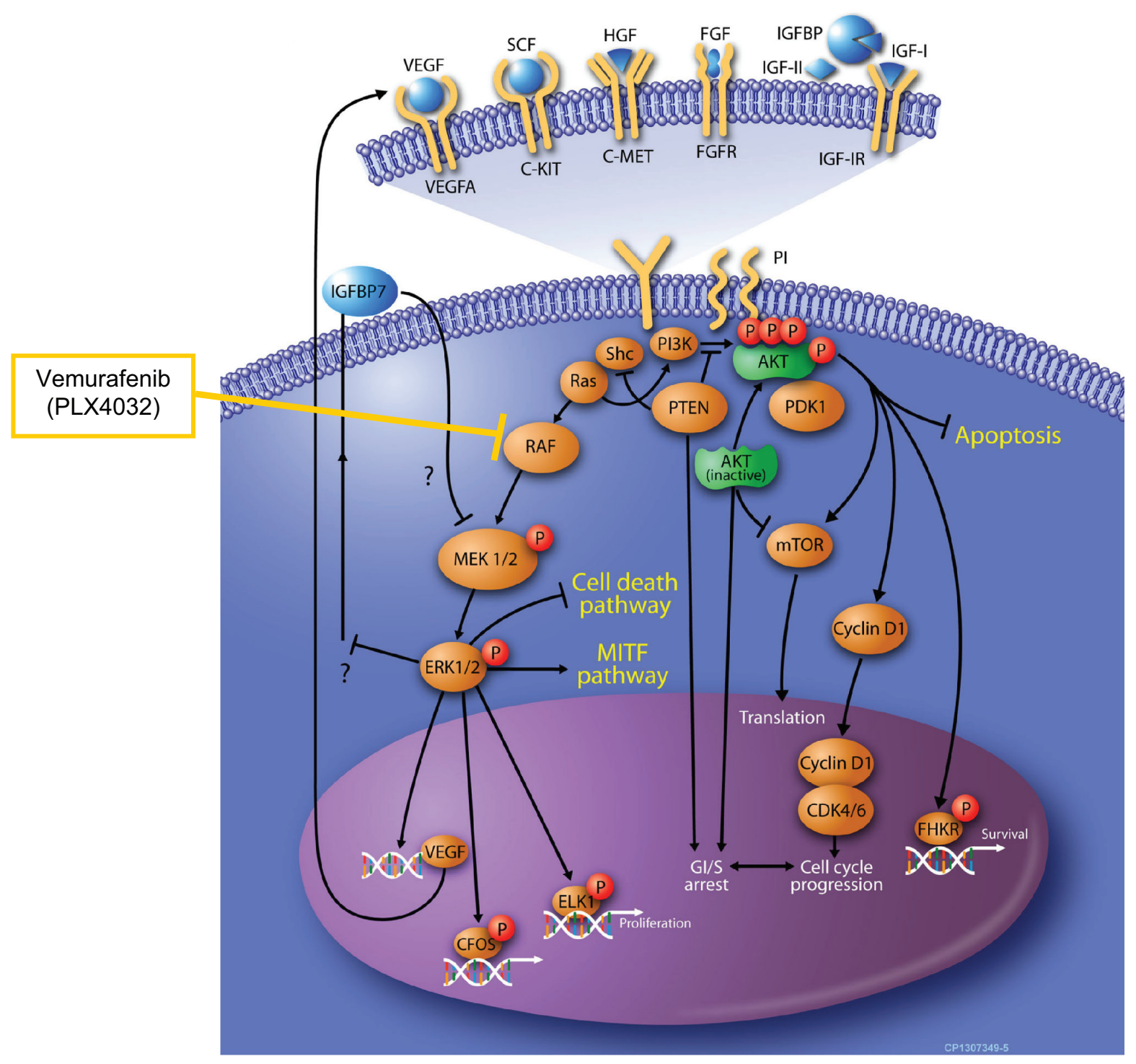

Figure I The B-RAF and N-RAS pathways for the development of malignant melanoma.

C2008. Elsevier. Reproduced with permission from Sekulic A, Haluska Jr P, Miller AJ et al. Malignant melanoma in the 2 Ist century: the emerging molecular landscape. Mayo Clin Proc. 2008:83(7):825-846. 
Early signs of melanoma can be remembered by the "ABCDE" acronym, which stands for:

- Asymmetrical shape, in that the lesion has two very dissimilar appearing halves

- Border irregularity or scalloped or nodular edges

- Color variation within the same lesion

- Diameter greater than $6 \mathrm{~mm}$ or $1 / 4 \mathrm{inch}$

- Evolving over time.

Although this acronym is helpful, unique subtypes like amelanotic melanoma may develop in the absence of any of these criteria and require a high index of suspicion. If metastatic melanoma is detected, symptoms are nonspecific and often include swollen lymph nodes, unintentional weight loss, headaches, nausea, and vomiting.

Any lesion exhibiting aspects of "ABCDE" should be examined and possibly excised by a dermatologist. Dermoscopy involves utilizing a powerful magnifying lens with or without a fluid interface to more closely analyze the in vivo architecture and patterns of pigmentation in a suspicious lesion. Major criteria for the identification of melanoma include regression erythema, radial streaming, a gray-blue or blue-white veil, irregularly distributed pseudopods, and an irregular pigment network. ${ }^{27}$

Histologic examination by a board-certified pathologist or dermatopathologist is the gold standard for diagnosis of melanoma. Although no stain has demonstrated 100\% sensitivity or specificity, traditional positive stains include S-100, HMB-45, MART-1/melan-A, tyrosinase, and MART- $1 .{ }^{28}$ Another diagnostic tool analyzes chromosomes 6 and 11 through fluorescent in situ hybridization by targeting centromeres 6, 6q, 6p, and $11 \mathrm{q}$, demonstrating $86.7 \%$ sensitivity and $95.4 \%$ specificity. ${ }^{29}$

\section{Current immunotherapies for metastatic melanoma}

All T cells, both cytotoxic $\mathrm{CD} 8$ and helper $\mathrm{CD} 4$ cells, require an intricate set of receptor-ligand interactions to enable proliferation and subsequent effector function. The first step in T-cell activation requires a $\mathrm{T}$ cell to recognize its compatible peptide ligand presented in the framework of a major histone compatibility complex (MHC). Consequently, to enable full and unbridled activation of a CD4 or CD8 cell, a costimulatory molecule present on the aforementioned MHC must transmit an additional signal. This secondary molecular correspondence is produced between $\mathrm{B} 7$ on the MHC and a receptor known as CD28 on the T cell..$^{30}$ Only when both interactions occur in this synergistic manner can a $\mathrm{T}$ cell begin to propagate, initiate gene transcription, establish function, and scan the immune system for antigenic molecules. ${ }^{30}$

Cytotoxic T lymphocyte antigen 4 (CTLA-4) is an immunoglobulin (Ig) positioned on the surface of CD4 helper T cells. CTLA-4 serves to transmit an inhibitory influence on $\mathrm{T}$ cells and act as a negative regulator of T-cell function. As mentioned earlier, CD28 conducts an activating signal enabling a positive regulation of T-cell function. Both CTLA-4 and CD28 bind to B7 on the antigen-presenting cells. Once T-cell activation is complete, CTLA-4 becomes upregulated and may outcompete CD28 for the binding to B7 and thereby exert a predominant suppression of T-cell effector function. ${ }^{31}$ Ipilimumab $\left(\operatorname{IgG}_{1}\right)$ and tremelimumab (noncompliment-fixing $\operatorname{IgG}_{2}$ ) are both fully human monoclonal antibodies that work by selectively binding to, and inhibiting the function of, CTLA-4. This subsequently releases the inhibitory influence and allows full enhancement and utility of the T-cell response. ${ }^{31}$ Inhibiting this negative switch causes a break in peripheral tolerance to self-antigens and self-tissue, inducing an antitumor response.

\section{Ipilimumab (MDX-0 I0)}

Obtaining improvement in the OS of metastatic melanoma remains an imponderable goal. One of the first phase III trials investigating ipilimumab looked at 676 patients with unresectable stage III or IV metastatic melanoma. The median OS for those receiving ipilimumab/gp100 vaccine was 10.0 months (95\% confidence interval [CI] 8.5-11.5) as compared with 6.4 months ( $95 \%$ CI 5.5-8.7) for those receiving gp 100 vaccine alone. Interestingly, the OS for ipilimumab alone was 10.1 months ( $95 \%$ CI 8.0-13.8), suggesting that ipilimumab not only works independently of the gp 100 vaccine but also may improve survival if administered alone. ${ }^{32}$

In 2011, a randomized phase III trial demonstrated an OS of $47 \%, 28.5 \%$, and $20.8 \%$ at years 1,2 , and 3, respectively, in patients receiving ipilimumab-dacarbazine, compared with $36 \%, 17.9 \%$, and $12.2 \%$ in the dacarbazine-placebo group (hazard ratio for death $0.72 ; P<0.001$ ). ${ }^{6}$ The composition of immune-related adverse effects in this study differed from those in previous clinical trials with a higher incidence of hepatotoxicity and a lower incidence of colitis, which may be related to the known hepatotoxic effect of dacarbazine. ${ }^{6}$

Following the aforementioned trial, a retrospective analysis was published in 2012 that analyzed OS rates in treatment-naïve and previously treated patients with ipilimumab in the same clinical trial. The clinical endpoint was to determine the effects of previous systemic anticancer treatment on ipilimumab's efficacy and safety. Median OS for the 
treatment-naïve group receiving ipilimumab was 30.5 months, with survival rates of $69.4 \%, 62.9 \%$, and $56.9 \%$ at 12,18 , and 24 months, respectively. The OS was 13.6 months with rates of $50.0 \%, 37.7 \%$, and $28.5 \%$ in the previously treated patients at 12, 18, and 24 months. An important implication evidenced by this trial suggests that prior systemic treatment for metastatic melanoma does not significantly affect the clinical or objective response to ipilimumab. ${ }^{33}$ Currently, an induction regime comprising $10 \mathrm{mg} / \mathrm{kg}$ every third week for 4 months, in addition to a maintenance dose of $10 \mathrm{mg} / \mathrm{kg}$ every 12 weeks beginning at week 24 , has emanated as the most successful and tolerable schedule and is being utilized in many ongoing phase II and phase III clinical trials. ${ }^{34}$

\section{Tremelimumab (CP-675,206)}

Competing with ipilimumab for recognition in the field of anti-CTLA-4 antibodies, a phase III trial of tremelimumab was recently completed. Preliminary results revealed an OS of 11.76 months with tremelimumab and 10.71 months with standard chemotherapy, with the difference not being statistically significant. ${ }^{35}$ Conversely, complete remission was noted in $1.8 \%$ of those treated with standard chemotherapy versus $1.5 \%$ complete remission in tremelimumab-treated patients, indicating similar efficacy between the two arms. $^{35}$

Despite meager results and three treatment-related deaths in the tremelimumab arm, another study investigated the efficacy of tremelimumab versus interferon-2b. ${ }^{36}$ Criteria established to determine clinical improvement included complete response rates (all detectable tumor has disappeared) and partial response rates (at least a 50\% decrease in total tumor volume), with objective response rate being a combination of the two. In this study, the best objective response rate was $24 \%$ with four complete and five partial responses and a median OS of 21 months. ${ }^{36}$ Following the final analysis of the clinical data obtained from these trials, tremelimumab was abandoned as a potential and viable option for the treatment of unresectable and metastatic melanoma, due to low response rates.

\section{Vemurafenib (PLX4032)}

The well-known RAS-RAF-MEK-ERK signaling pathway mediates signaling for the growth and development of melanoma. Currently, the field of immunotherapy is taking aim at downstream effector pathways involving $B R A F$. BRAF is a proto-oncogene that becomes mutated in nearly $70 \%$ of melanoma cases. ${ }^{37,38}$ These $B R A F$ V600E mutations contain a glutamic acid that is substituted for valine, leading to sustained and prolonged phosphorylation of the subsequent ERK pathway. ${ }^{39}$

Vemurafenib, derived from V600E-mutated $B R A F$ inhibition, is an orally administered adenosine triphosphate $B R A F$ competitive antagonist specific for the V600E isoform. ${ }^{4}$ Preclinical trials adequately demonstrated vemurafenib's ability to induce cell cycle arrest and apoptosis in those variants harboring the $B R A F$ V600E mutation. This mechanism leads to the inhibition of ensuing ERK phosphorylation and cellular multiplication of malignant cells by day 15 (Figure 1). ${ }^{40}$ Recently, the results of a large worldwide multicenter phase III trial were published, outlining the first survival data for vemurafenib compared with dacarbazine. ${ }^{41}$ Results revealed that vemurafenib therapy decreased mortality by $63 \%$ and reduced tumor progression by $74 \%$. Additionally, vemurafenib demonstrated a 6 -month OS rate of $84 \%$ versus $64 \%$ in the dacarbazine group $(P<0.001)$. Furthermore, the progression-free interval, as defined by the time between randomization and documented disease progression, was 5.3 months in the vemurafenib group versus 1.6 months with dacarbazine $(P<0.001) .{ }^{41}$

\section{Intralesional therapies}

Direct therapeutic injection of an immunmodulator into the lesion comprises the basic tenants of IL therapy. Described in a case report of a 77-year-old man, 64 intracutaneous and pulmonary metastatic deposits were inoculated with the Bacille Calmette-Guérin (BCG) vaccine over an 8-month period of time. Surprisingly, all injected lesions resolved. Additionally, an upregulation of an antitumor immune response occurred, which led to a systemic improvement in remote, uninjected metastases with $50 \%$ regression in pulmonary metastases. ${ }^{42}$ Unfortunately, interest dwindled once further trials demonstrated type I anaphylactic reactions to the injections and even death occurring secondary to dissemination of BCG. Thus, overall, there was a failure to substantiate any compelling clinical advantage to these findings. ${ }^{43}$ Regardless of the perceived failure of direct injection of BCG, a new subgroup of IL therapies is being investigated to determine possible clinical benefits in metastatic melanoma. ${ }^{44}$

\section{Allovectin-7}

Representing a first-in-class immunotherapy, Allovectin-7 is a combined bicistronic plasmid/lipid composite encoding the DNA sequence of human leukocyte antigen-B7 heavy chain and $\beta 2$-microglobulin. Both of these components are essential features of any MHC-1. ${ }^{45}$ In melanoma cancer cells, there is 
a diminished expression of MHC-1, enabling malignant cells to circumvent recognition by activated T cells. Allovectin-7 was designed to enhance the allogenic expression of MHC-1 antigen following direct IL injection. ${ }^{45}$ Upon administration, this drug has produced a five-fold rise in cytotoxic $\mathrm{T}$ cells, increased and re-established MHC-I molecules, and stimulated a proinflammatory reaction. ${ }^{46,47}$

In a recent phase II trial, the objective response rate, defined as those achieving a complete response or partial response, was $12 \%$, with a median duration of response of 13.8 months. ${ }^{48}$ Additionally, researchers performed a tissue biopsy from two responding patients that revealed no histological evidence of melanoma. Finally, of the 127 patients who received a high dose $(2 \mathrm{mg})$ of Allovectin- 7 , no one exhibited any grade III or IV adverse effects, and no dropouts occurred due to side effects. ${ }^{48}$ Currently, a phase III trial of Allovectin-7 is under way, involving direct comparison against standard of care dacarbazine/ temozolomide. $^{48}$

\section{OncoVEX GM-CSF}

Another direct IL therapy being investigated for the treatment of metastatic melanoma is OncoVEX (talimogene laherparepvec). This compound is a second-generation herpes simplex virus encoding granulocyte macrophage colony-stimulating factor (GM-CSF) yielding oncolytic properties. This recombinant virus, once injected into the tumor cells, is believed to selectively replicate exclusively in those cells, express GM-CSF, and subsequently cause lysis and destruction. ${ }^{49}$ These fragmented cells are engulfed by antigen-presenting cells and activate an antimelanoma immune response that is further enhanced by GM-CSF. ${ }^{50}$

In a completed phase III study of OncoVEX, 20\% obtained a complete response, whereas an objective response rate was achieved in nearly $28 \%$ of patients. ${ }^{51}$ Another significant finding included a $92 \%$ durable response, lasting a minimum of 6 months, with the majority of patients experiencing responses in the range of 18-40 months. Two similarities can be noted between the aforementioned Allovectin-7 trial and the OncoVEX trial. First, a number of patients in the OncoVEX trial also obtained complete resolution of some visceral metastases, leading to resolution of those specific deposits. Secondly, regression was demonstrated not only in the injected lesions but also in distal tumors, leading to the thought that a secondary immune-mediated antitumor effect may exist in these scenarios. Finally, posttreatment phenotypic evaluation of cells collected from tissue samples in individuals receiving OncoVEX and those not receiving the vaccine suggested differences between T-cell compositions. In the treatment group, an increase in regression of melanoma-associated antigen-recognized $\mathrm{T}$ cells was noted, compared with the control. Additionally, a noticeable decrease in regulatory $\mathrm{T}$ cells and suppressive $\mathrm{T}$ cells in the injected lesions was noted versus untreated lesions. Because of these promising results, a randomized phase III clinical trial is under way. ${ }^{52}$

\section{Rose bengal (PV-I0)}

Rose bengal is commonly known for its role as a chemical stain. It is being investigated as a chemoablative agent administered as an IL injection for the treatment of various cancers, including melanoma. ${ }^{53}$ The formulation used is $10 \%$ rose bengal in normal saline (PV-10) and is a small molecule fluorescein byproduct that remains unmetabolized in the body. PV-10 sustains a 30-minute half-life and is excreted through the biliary system. Similar to OnvoVEX, PV-10 takes preferential aim at cancerous cells by transiting directly through the plasmalemma of the malignant cell and accumulating in the lysosomes, resulting in their activation. ${ }^{54}$ This activation causes autolysis within 60 minutes of exposure, leading to fragmentation of the tumor. These fragments are then taken up by antigen-presenting cells presented to activated $\mathrm{T}$ and $\mathrm{B}$ cells, causing an underlying collateral "bystander" effect. ${ }^{53}$ This mechanism is unique in that there is a highly selective tumor ablation, relatively immediate reduction in tumor burden, and concomitant activation of the immune system. ${ }^{53}$

In a recent trial, of the 26 total lesions injected with PV-10, 25 were evaluated in follow-up. Results revealed that $36 \%$ of lesions (nine of 25) demonstrated complete response, $12 \%$ (three of 25 ) showed partial response, $28 \%$ (seven of 25 ) exhibited stability of the lesions, and $24 \%$ (six of 25 ) displayed progressive disease. ${ }^{55}$ Overall, this suggested that IL injection of PV-10 leads to regression in up to $48 \%$ of metastatic deposits. Furthermore, the distant noninjected lesions were also evaluated in this study and exhibited an objective response rate of $27 \% .{ }^{55}$ Researchers noted a strong positive correlation between the response rate of target and nontarget lesions in an individual. This suggests that those who responded well to the IL therapy at the target site also exhibited good response in the nontarget lesions, again supporting the presence of a bystander effect. ${ }^{55}$

The next phase II trial revealed a 33\% complete response rate, $28 \%$ partial response rate, $18 \%$ with stability of their disease, and an objective response rate of $49 \%$ in target lesions. ${ }^{56}$ The locoregional control of disease 
(complete + partial + stable) was $71 \%$. Additional analyses of those who exhibited complete response also demonstrated a considerably longer progression-free survival time (11.1 months) compared with those with progressive or even stable disease (2.7 and 2.8, respectively). ${ }^{56}$

In both studies, PV-10 was extremely well tolerated by participants, with no severe adverse side effects noted. No individuals withdrew from the study or discontinued treatment. The most common adverse effect noted in both studies was pain and mild-to-moderate inflammation at the injection site. ${ }^{55,56}$

\section{Further research and challenges}

Melanoma is very complex and remains relatively resilient to most therapeutic modalities. Most forms of immunotherapy, whether for melanoma or not, are unique, in the sense that they need time to work. However, when these responses occur, they tend to be more durable and longer lasting. ${ }^{1}$ Further trials are needed to investigate the numerous possibilities for combination and adjuvant therapy.

Recently, a great hope for anticancer therapy has been to identify a weakness in the tumor's molecular pathway and target those specific weak points. Although relative success is often achieved initially, the overall results seem to be lacking. After the remarkable initial trials with vemurafenib, subsequent follow-up revealed many individuals with complete regression of their tumors were experiencing recurrence. ${ }^{57}$ It was found that the resistant tumors were able to bypass the pathway inhibition by developing a new mutated kinase-binding domain. ${ }^{58}$ Many believe that the next step in antitumor therapy will be the development of a second-generation drug designed to block the tumor's most common escape route, restoring the growth pathway by activating a downstream protein called MEK. ${ }^{59}$

Table I Summary of the therapeutic target, relevant clinical trials, and common side effects of select melanoma immunotherapies

\begin{tabular}{|c|c|c|c|c|}
\hline Immunotherapy & Target & Current trials & Completed trials & Side effects \\
\hline Ipilimumab* & $\begin{array}{l}\text { Noncompliment-fixing } \lg \mathrm{G}_{2} \text { selectively } \\
\text { binds to and inhibits CTLA-4, releasing } \\
\text { an inhibitory influence and allowing full } \\
\text { activation of the T-cell response }\end{array}$ & $\begin{array}{l}\text { Currently, } 67 \text { trials are under } \\
\text { way investigating combination } \\
\text { therapy, efficacy, and safety. } \\
\text { Search http://www.clinicaltrials. } \\
\text { gov for more information }\end{array}$ & $\begin{array}{l}\text { Phase II } \\
\text { NCT00289640,** } \\
\text { NCT00289627,** } \\
\text { NCT00729950,** } \\
\text { NCT00I35408** }\end{array}$ & $\begin{array}{l}\text { Exanthem, diarrhea, pruritis, } \\
\text { colitis, inflammatory } \\
\text { hepatotoxicity, hypophysitis, } \\
\text { episcleritis }{ }^{66}\end{array}$ \\
\hline Tremelimumab & $\begin{array}{l}\text { Noncompliment-fixing } \operatorname{lgG}_{2} \text { that } \\
\text { selectively binds to and inhibits } \\
\text { CTLA-4, releasing an inhibitory } \\
\text { influence and allowing full activation } \\
\text { of the T-cell response }\end{array}$ & Phase I NCT0I I 03635** & $\begin{array}{l}\text { Phase III trial - } \\
\text { abandoned secondary } \\
\text { to low response rates }\end{array}$ & $\begin{array}{l}\text { Exanthem, diarrhea, pruritis, } \\
\text { colitis, inflammatory } \\
\text { hepatotoxicity, hypophysitis, } \\
\text { episcleritis }{ }^{66}\end{array}$ \\
\hline Vemurafenib* & $\begin{array}{l}\text { Selective BRAF kinase inhibitor } \\
\text { for melanoma containing the } \\
\text { BRAF }^{\mathrm{V} 600 \mathrm{E}} \text { mutation }\end{array}$ & $\begin{array}{l}\text { Currently, } 31 \text { trials are under } \\
\text { way investigating combination } \\
\text { therapy, efficacy, and safety. } \\
\text { Search http://www.clinicaltrials. } \\
\text { gov for more information }\end{array}$ & $\begin{array}{l}\text { Numerous trials have } \\
\text { concluded, including } \\
\text { a recent phase II trial } \\
\text { NCT00949702** }\end{array}$ & $\begin{array}{l}\text { Squamous cell carcinoma, } \\
\text { verrucous keratoses, } \\
\text { lobular panniculitis, } \\
\text { photosensitivity, keratosis } \\
\text { pilaris, rash, fatigue, } \\
\text { alopecia, keratoacanthoma, } \\
\text { pruritis, nausea, diarrhea, } \\
\text { hyperkeratosis } \\
67,68\end{array}$ \\
\hline Allovectin-7 & $\begin{array}{l}\text { Intratumoral injection of a plasmid/lipid } \\
\text { composite encoding HLA-B7 } \\
\text { and B2 microglobulin that expresses } \\
\text { foreign antigens and causes a local } \\
\text { inflammatory response }\end{array}$ & $\begin{array}{l}\text { Phase III NCT00395070,** } \\
\text { phase III NCT00003647** }\end{array}$ & $\begin{array}{l}\text { Phase II } \\
\text { NCT00044356** }\end{array}$ & $\begin{array}{l}\text { Injection site pain, rigors, } \\
\text { fatigue, injection site } \\
\text { erythema, myalgia, pyrexia, } \\
\text { arthralgia, headache }{ }^{48}\end{array}$ \\
\hline OncoVEX & $\begin{array}{l}\text { Intratumoral injection of herpes } \\
\text { simplex-I virus encoding GM-CSF } \\
\text { that selectively replicates within } \\
\text { tumor cells, causing necrosis and } \\
\text { lysis of the cell }\end{array}$ & $\begin{array}{l}\text { Phase III NCT00769704,** } \\
\text { phase III NCT0I368276** }\end{array}$ & $\begin{array}{l}\text { Phase II } \\
\text { NCT00289016** }\end{array}$ & $\begin{array}{l}\text { Fever, chills, fatigue/ } \\
\text { malaise, pain at injection } \\
\text { site, headache, vomiting, } \\
\text { diarrhea }{ }^{52,69}\end{array}$ \\
\hline PV-IO & $\begin{array}{l}\text { Intratumoral injection, leading to } \\
\text { accumulation within the lysosome } \\
\text { and subsequent autolysis of the } \\
\text { tumor cell }\end{array}$ & $\begin{array}{l}\text { Cleared for phase III trials } \\
\text { to begin in late } 2012\end{array}$ & $\begin{array}{l}\text { Phase II } \\
\text { NCT00521053,** } \\
\text { phase I } \\
\text { NCT002198438** }\end{array}$ & $\begin{array}{l}\text { Pain at treatment site, } \\
\text { local inflammation, pruritis, } \\
\text { photosensitivity }{ }^{55}\end{array}$ \\
\hline
\end{tabular}

Notes: *Received Food and Drug Administration approval for treatment of unresectable or metastatic melanoma (201 I); **National Institutes of Health ClinicalTrials.gov reference number.

Abbreviations: CTLA-4, cytotoxic T lymphocyte antigen 4; GM-CSF, granulocyte macrophage colony-stimulating factor; Ig, immunoglobulin. 
Possible blockades of sequential or additional downstream targets may provide the answer to overcoming the evolving resistance pathways in these molecular tumors. To prolong the benefits across months to years, it may become necessary to devise repeated complex treatment regimens, each tailored at a patient's own evolving tumor.

With the ever-increasing and crippling cost of medical therapies, one has to question the availability and accessibility that patients have to these agents. The monthly cost of vemurafenib is estimated at $\$ 9400$, with a total cost of $\$ 56,400$ for a 6 -month treatment. In addition, a seemingly insignificant \$120-\$150 will be incurred for genetic testing to determine whether one carries the mutated V600E $B R A F$ gene. ${ }^{60}$ Furthermore, the anticipated reluctance of both government and private insurance companies to cover these agents seems almost certain. At this point, the challenge becomes developing an agent that not only decreases morbidity and mortality but also is accessible and synergistically complements the economical demands of health care.

\section{Patient-focused considerations}

OS, complete response rates, and months of progressionfree disease are common benchmarks for clinical trials. However, it remains essential to not lose perspective of quality of life (QOL) issues that represent an independent predictor of survival in nearly all cancers. ${ }^{61}$ In addition, QOL issues may become a primary concern in clinical decisions for situations where survival benefits with current therapy are modest. For some, the number of days, months, or years given following a diagnosis of metastatic melanoma may not be as concerning as the quality of that time period and the absence of underlying side effects (see Table 1). In one study of patients with melanoma, those who demonstrated optimism and positivity about their disease prognosis or who minimized the influence of cancer in their daily lives were found to live longer than those who did not. ${ }^{62}$ Patients should be involved in the choice of treatment type after a thorough informed consent process has been undertaken by the treating team to maximize autonomy and foster feelings of teamwork. This simple act seems to empower patients and provide a more optimistic outlook on the disease process. ${ }^{63}$ Secondly, the amount of supportive therapy and social support received from clinicians, family, and friends also correlates highly with an increased QOL. ${ }^{64}$ Interestingly, individuals undergoing complete lymph node dissections demonstrated lower QOL than those receiving a sentinel lymph node biopsy. ${ }^{65}$ This is an example that demonstrates the importance of weighing potential benefits and risks of any treatment regimen, and taking into consideration the impact on QOL.

Anatole Broyard ${ }^{70}$ wrote: "To the typical physician, my illness is a routine incident in his rounds, while for me it's the crisis of my life." Combining the high mortality rate and young age at which melanoma can be diagnosed, researchers have noted increased anxiety, psychological strain, and tumor-associated fears that may, in fact, postpone the quest for medical evaluation in patients. ${ }^{71}$ Identified risk factors that may forecast the likelihood of one to experience increased levels of psychological stress included female gender and advanced age at diagnosis. Counterintuitively, depth of melanoma at diagnosis was correlated with lower levels of anxiety. ${ }^{72}$ Key issues for researchers and clinicians alike to keep in perspective are those factors that contribute to the overall apprehension associated with a diagnosis of melanoma. Those factors conferring the greatest anxiety in general include the prognosis, the patient's own fears of death, and the attitude of the diagnosing physician. ${ }^{73}$ Other factors, like failure of previous treatments, fear of pain, and previous experiences with melanoma and other cancers, ranked lowest on the list of anxiety-provoking factors. ${ }^{73}$ These issues remind us all that, first and foremost, before any treatment with these novel immunotherapies begins, every patient needs reassurance and confidence from their physician, which ensues with effective communication techniques and a respectful doctor-patient relationship.

\section{Conclusion}

New and evolving immunotherapeutic agents are yielding meaningful and promising clinical responses in patients with metastatic melanoma. Numerous clinical questions remain unanswered, including optimal dosing regimens, synergistic combination therapy, and the management of adverse effects. As research continues, consideration should be given to the development of predictive biomarkers to determine which therapy may be most appropriate. Furthermore, additional trials are needed to investigate combination therapies and drug resistance in order to maximize clinical outcomes. It should be emphasized that despite the widespread research and clinical excitement produced by these agents, their actual efficacy remains relatively poor. It is plausible that part of the reason why Food and Drug Administration approval was obtained for ipilimumab and vemurafenib resulted, in part, from a glimpse of optimism during an otherwise stagnant decade of developments in melanoma drug therapy. Finally, regardless of how effective and durable response 
rates appear, the economical availability of these agents in mainstream medicine likely poses the greatest impediment to their widespread use.

\section{Disclosure}

The authors report no conflicts of interest in this work.

\section{References}

1. Sznol M. Advances in the treatment of metastatic melanoma: new immunomodulatory agents. Semin Oncol. 2012;39:192-203.

2. Balch CM, Gershenwald JE, Soong SJ, et al. Final version of 2009 AJCC melanoma staging and classification. J Clin Oncol. 2009;27(36):6199-6206.

3. Hanaizi Z, van Zwieten-Boot B, Calvo G, et al. The European Medicines Agency review of ipilimumab (Yervoy) for the treatment of advanced (unresectable or metastatic) melanoma in adults who have received prior therapy: summary of the scientific assessment of the Committee for Medicinal Products for Human Use. Eur J Cancer. 2011;48: 237-242.

4. FDA. Notable FY 2011 Approvals. 2011; http://www.fda.gov/ AboutFDA/ReportsManualsForms/Reports/ucm276413.htm Accessed August 14, 2012.

5. Eggermont AM, Robert C. New drugs in melanoma: it's a whole new world. Eur J Cancer. 2011;47:2150-2157.

6. Robert C, Thomas L, Bondarenko I, et al. Ipilimumab plus dacarbazine for previously untreated metastatic melanoma. $N$ Engl $\mathrm{J} \mathrm{Med}$. 2011;364(26):2517-2526.

7. Finn L, Markovic SN, Joseph RW. Therapy for metastatic melanoma: the past, present, and future. BMC Medicine. 2012;10:23-23.

8. Gilchrest BA, Eller MS, Geller AC, Yaar M. The pathogenesis of melanoma induced by ultraviolet radiation. $N$ Engl J Med. 1999;340(17):1341-1348.

9. Weinstock MA. Epidemiology, etiology, and control of melanoma. Med Health R I. 2001;84(7):234-236.

10. Gandini S, Sera F, Cattaruzza MS, et al. Meta-analysis of risk factors for cutaneous melanoma: II. Sun exposure. Eur J Cancer. 2005;41(1):45-60.

11. Singh SD, Ajani UA, Johnson CJ, et al. Association of cutaneous melanoma incidence with area-based socioeconomic indicators-United States, 2004-2006. J Am Acad Dermatol. 2011;65:S58-S68.

12. Geller AC, Swetter SM, Brooks K, Demierre MF, Yaroch AL. Screening, early detection, and trends for melanoma: current status (2000-2006) and future directions. J Am Acad Dermatol. 2007;57:555-572.

13. Swerdlow AJ, Weinstock MA. Do tanning lamps cause melanoma? An epidemiologic assessment. J Am Acad Dermatol. 1998;38(1):89-98.

14. Dore JF, Chignol MC. Tanning salons and skin cancer. Photochem Photobiol Sci. 2012;11(1):30-37.

15. International Agency for Research on Cancer Working Group on artificial ultraviolet light and skin cancer. The association of use of sunbeds with cutaneous malignant melanoma and other skin cancers: a systematic review. Int J Cancer. 2007;120(5):1116-1122.

16. Lazovich D, Vogel RI, Berwick M, Weinstock MA, Anderson KE, Warshaw EM. Indoor tanning and risk of melanoma: a case-control study in a highly exposed population. Cancer Epidemiol Biomarkers Prev. 2010;19(6):1557-1568.

17. Hayward NK. Genetics of melanoma predisposition. Oncogene. 2003;22(20):3053-3062.

18. Aitken J, Welch J, Duffy D, et al. CDKN2 A variants in a population-based sample of Queensland families with melanoma. J Natl Cancer Inst. 1999;91(5):446-452.

19. Mosse I, Kostrova L, Subbot S, Maksimenya I, Molophei V. Melanin decreases clastogenic effects of ionizing radiation in human and mouse somatic cells and modifies the radioadaptive response. Radiat Environ Biophys. 2000;39(1):47-52.
20. Wachsmuth RC, Turner F, Barrett JH, et al. The effect of sun exposure in determining nevus density in UK adolescent twins. $J$ Invest Dermatol. 2005;124:56-62.

21. Rivers JK. Is there more than one road to melanoma? Lancet. 2004;363(9410):728-730.

22. Gill M, Celebi JT. B-RAF and melanocytic neoplasia. J Am Acad Dermatol. 2005;53(1):108-114.

23. Ellerhorst JA, Greene VR, Ekmekcioglu S, et al. Clinical correlates of NRAS and BRAF mutations in primary human melanoma. Clin Cancer Res. 2011;17(2):229-235.

24. Curtin JA, Fridlyand J, Kageshita T, et al. Distinct sets of genetic alterations in melanoma. N Engl J Med. 2005;353(20):2135-2147.

25. Devitt B, Liu W, Salemi R, et al. Clinical outcome and pathological features associated with NRAS mutation in cutaneous melanoma. Pigment Cell Melanoma Res. 2011;24(4):666-672.

26. Edlundh-Rose E, Egyhazi S, Omholt K, et al. NRAS and BRAF mutations in melanoma tumours in relation to clinical characteristics: a study based on mutation screening by pyrosequencing. Melanoma Res. 2006;16:471-478.

27. Dal Pozzo V, Benelli C, Roscetti E. The seven features for melanoma: a new dermoscopic algorithm for the diagnosis of malignant melanoma. Eur J Dermatol. 1999;9(4):303-308.

28. Ohsie SJ, Sarantopoulos GP, Cochran AJ, Binder SW. Immunohistochemical characteristics of melanoma. J Cutan Pathol. 2008;35(5):433-444.

29. Gerami P, Zembowicz A. Update on fluorescence in situ hybridization in melanoma: state of the art. Arch Pathol Lab Med. 2011;135:830-837.

30. Linsley PS, Nadler SG. The clinical utility of inhibiting CD28-mediated costimulation. Immunol Rev. 2009;229:307-321.

31. Bour-Jordan H, Esensten JH, Martinez-Llordella M, Penaranda C, Stumpf M, Bluestone JA. Intrinsic and extrinsic control of peripheral T-cell tolerance by costimulatory molecules of the CD28/B7 family. Immunol Rev. 2011;241(1):180-205.

32. Hodi FS, O'Day SJ, McDermott DF, et al. Improved survival with ipilimumab in patients with metastatic melanoma. $N$ Engl $\mathrm{J} \mathrm{Med}$. 2010;363:711-723.

33. Thompson JA, Hamid O, Minor D, et al. Ipilimumab in treatmentnaive and previously treated patients with metastatic melanoma: retrospective analysis of efficacy and safety data from a phase II trial. J Immunother. 2012;35(1):73-77.

34. Wolchok JD, Neyns B, Linette G, et al. Ipilimumab monotherapy in patients with pretreated advanced melanoma: a randomised, double-blind, multicentre, phase 2, dose-ranging study. Lancet Oncol. 2010;11(2):155-164.

35. Ribas AH, Kefford R, Punt CJ, Haanen JB, Marmol M, Garbe C, et al. Phase III, open-label, randomized, comparative study of tremelimumab (CP-675,206) and chemotherapy (temozolomide [TMZ] or dacarbazine [DTIC]) in patients with advanced melanoma. $J$ Clin Oncol. 2008;20:9011.

36. Tarhini AA, Cherian J, Moschos SJ, et al. Safety and efficacy of combination immunotherapy with interferon alfa- $2 \mathrm{~b}$ and tremelimumab in patients with stage IV melanoma. J Clin Oncol. 2012;30(3):322-328.

37. Cox AD, Der CJ. Ras history: the saga continues. Small Gtpases. 2010;1(1):2-27.

38. Karasarides M, Chiloeches A, Hayward R, et al. B-RAF is a therapeutic target in melanoma. Oncogene. 2004;23:6292-6298.

39. Flaherty KT, McArthur G. BRAF, a target in melanoma: implications for solid tumor drug development. Cancer. 2010;116(21):4902-4913.

40. Yang H, Higgins B, Kolinsky K, et al. RG7204 (PLX4032), a selective BRAFV600E inhibitor, displays potent antitumor activity in preclinical melanoma models. Cancer Res. 2010;70(13):5518-5527.

41. Chapman PB, Hauschild A, Robert C, et al. Improved survival with vemurafenib in melanoma with BRAF V600E mutation. $N$ Engl J Med. 2011;364(26):2507-2516.

42. Mastrangelo MJ, Bellet RE, Berkelhammer J, Clark WH Jr. Regression of pulmonary metastatic disease associated with intralesional BCG therapy of intracutaneous melanoma metastases. Cancer. 1975;36(4):1305-1308. 
43. Agarwala SS, Neuberg D, Park Y, Kirkwood JM. Mature results of a phase III randomized trial of bacillus Calmette-Guerin (BCG) versus observation and BCG plus dacarbazine versus BCG in the adjuvant therapy of American Joint Committee on Cancer Stage I-III melanoma (E1673): a trial of the Eastern Oncology Group. Cancer. 2004;100(8):1692-1698.

44. Good LM, Miller MD, High WA. Intralesional agents in the management of cutaneous malignancy: a review. J Am Acad Dermatol. 2011;64(2):413-422.

45. Bedikian AY, Del Vecchio M. Allovectin-7 therapy in metastatic melanoma. Expert Opin Biol Ther. 2008;8:839-844.

46. Nabel GJ, Gordon D, Bishop DK, et al. Immune response in human melanoma after transfer of an allogeneic class I major histocompatibility complex gene with DNA-liposome complexes. Proc Natl Acad Sci U S A. 1996;93(26):15388-15393.

47. Horton HM, Dorigo O, Hernandez P, Anderson D, Berek JS, Parker SE. IL-2 plasmid therapy of murine ovarian carcinoma inhibits the growth of tumor ascites and alters its cytokine profile. J Immunol. 1999;163(12): 6378-6385.

48. Bedikian AY, Richards J, Kharkevitch D, Atkins MB, Whitman E, Gonzalez R. A phase 2 study of high-dose Allovectin-7 in patients with advanced metastatic melanoma. Melanoma Res. 2010;20(3): 218-226.

49. Liu BL, Robinson M, Han ZQ, et al. ICP34.5 deleted herpes simplex virus with enhanced oncolytic, immune stimulating, and anti-tumour properties. Gene Ther. 2003;10:292-303.

50. Toda M, Martuza RL, Rabkin SD. Tumor growth inhibition by intratumoral inoculation of defective herpes simplex virus vectors expressing granulocyte-macrophage colony-stimulating factor. $\mathrm{Mol}$ Ther. 2000;2:324-329.

51. Kaufman HL, Kim DW, DeRaffele G, Mitcham J, Coffin RS, Kim-Schulze S. Local and distant immunity induced by intralesional vaccination with an oncolytic herpes virus encoding GM-CSF in patients with stage IIIc and IV melanoma. Ann Surg Oncol. 2010;17(3):718-730.

52. Kaufman HL, Bines SD. OPTIM trial: a Phase III trial of an oncolytic herpes virus encoding GM-CSF for unresectable stage III or IV melanoma. Future Oncol. 2010;6(6):941-949.

53. Mousavi H, Zhang X, Gillespie S, Wachter E, Hersey P. Rose bengal induces dual modes of cell death in melanoma cells and has clinical activity against melanoma. Melanoma Res. 2006;16:S8.

54. Wachter EDC, Harkins J, Fisher W, Scott T. Imaging photosensitizer distribution and pharmacology using multiphoton microscopy. Proc SPIE. 2002;4622:112.

55. Thompson JF, Hersey P, Wachter E. Chemoablation of metastatic melanoma using intralesional Rose Bengal. Melanoma Res. 2008;18(6):405-411.

56. Agarwala SS TJ, Smithers BM, Ross MI, et al. Chemoablation of metastatic melanoma with rose bengal (PV-10). J Clin Oncol. 2010;28(15S).
57. Kudchadkar R, Paraiso KH, Smalley KS. Targeting mutant BRAF in melanoma: current status and future development of combination therapy strategies. Cancer J. 2012;18:124-131.

58. Nazarian R, Shi H, Wang Q, et al. Melanomas acquire resistance to B-RAF(V600E) inhibition by RTK or N-RAS upregulation. Nature. 2010;468:973-977.

59. Kaiser J. Combining targeted drugs to stop resistant tumors. Science. 2011;331(6024):1542-1545.

60. MedPage Today [database on the Internet]. Available at http://www. medpagetoday.com/PublicHealthPolicy/FDAGeneral/28083. Accessed August 21, 2012.

61. Montazeri A. Quality of life data as prognostic indicators of survival in cancer patients: an overview of the literature from 1982 to 2008. Health Qual Life Outcomes. 2009;7:102.

62. Butow PN, Coates AS, Dunn SM. Psychosocial predictors of survival in metastatic melanoma. J Clin Oncol. 1999;17(7):2256-2263.

63. Rataj D, Jankowiak B, Krajewska-Kulak E, et al. Quality-of-life evaluation in an interferon therapy after radical surgery in cutaneous melanoma patients. Cancer Nurs. 2005;28:172-178.

64. Sigurdardottir V, Bolund C, Sullivan M. Quality of life evaluation by the EORTC questionnaire technique in patients with generalized malignant melanoma on chemotherapy. Acta Oncol. 1996;35(2):149-158.

65. de Vries M, Hoekstra HJ, Hoekstra-Weebers JE. Quality of life after axillary or groin sentinel lymph node biopsy, with or without completion lymph node dissection, in patients with cutaneous melanoma. Ann Surg Oncol. 2009;16(10):2840-2847.

66. Kahler KC, Hauschild A. Treatment and side effect management of CTLA-4 antibody therapy in metastatic melanoma. $J$ Dtsch Dermatol Ges. 2011;9(4):277-286.

67. Chu EY, Wanat KA, Miller CJ, et al. Diverse cutaneous side effects associated with BRAF inhibitor therapy: a clinicopathologic study. J Am Acad Dermatol. 2012 Dec;67(6):1265-1272.

68. Huang V, Hepper D, Anadkat M, Cornelius L. Cutaneous toxic effects associated with vemurafenib and inhibition of the BRAF pathway. Arch Dermatol. 2012;148(5):628-633.

69. Senzer NN, Kaufman HL, Amatruda T, et al. Phase II clinical trial of a granulocyte-macrophage colony-stimulating factor-encoding, second-generation oncolytic herpesvirus in patients with unresectable metastatic melanoma. J Clin Oncol. 2009;27:5763-5771.

70. Broyard A. Intoxicated by my Illness: and Other Writings on Life and Death. New York, NY: Ballantine; 1992.

71. Spiegel D. Cancer and depression. Br J Psychiatry Suppl. 1996(30): 109-116.

72. Brandberg Y, Mansson-Brahme E, Ringborg U, Sjoden PO. Psychological reactions in patients with malignant melanoma. Eur $J$ Cancer. 1995;31A(2):157-162.

73. Missiha SB, Solish N, From L. Characterizing anxiety in melanoma patients. J Cutan Med Surg. 2003;7(6):443-448.
ImmunoTargets and Therapy

\section{Publish your work in this journal}

ImmunoTargets and Therapy is an international, peer-reviewed open access journal focusing on the immunological basis of diseases, potential targets for immune based therapy and treatment protocols employed to improve patient management. Basic immunology and physiology of the immune system in health, and disease will be also covered. In addition, the journal will focus on the impact of manage-

\section{Dovepress}

ment programs and new therapeutic agents and protocols on patient perspectives such as quality of life, adherence and satisfaction. The manuscript management system is completely online and includes a very quick and fair peer-review system, which is all easy to use. Visit http://www.dovepress.com/testimonials.php to read real quotes from published authors. 